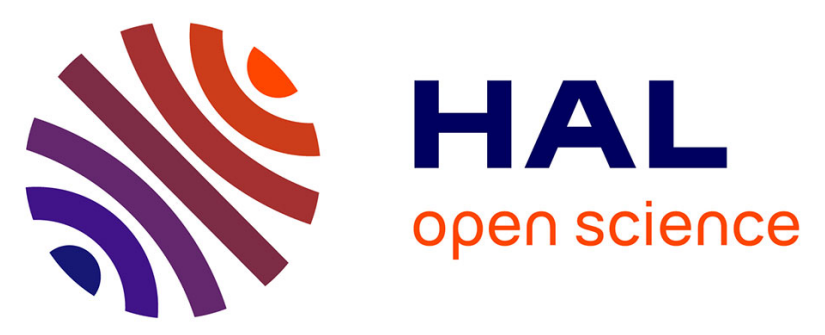

\title{
Stress induced linear dichroism of antiferromagnetic perovskites: KNif3, KCoF3 and RbCoF3. I. - Magnetic origin and evidence for domain twin-walls movements
}

\author{
J. Ferré, B. Briat, R.H. Petit, R.V. Pisarev, J. Nouet
}

\section{- To cite this version:}

J. Ferré, B. Briat, R.H. Petit, R.V. Pisarev, J. Nouet. Stress induced linear dichroism of antiferromagnetic perovskites: KNif3, KCoF3 and RbCoF3. I. - Magnetic origin and evidence for domain twinwalls movements. Journal de Physique, 1976, 37 (5), pp.503-508. 10.1051/jphys:01976003705050300 . jpa-00208445

\section{HAL Id: jpa-00208445 https://hal.science/jpa-00208445}

Submitted on 1 Jan 1976

HAL is a multi-disciplinary open access archive for the deposit and dissemination of scientific research documents, whether they are published or not. The documents may come from teaching and research institutions in France or abroad, or from public or private research centers.
L'archive ouverte pluridisciplinaire $\mathbf{H A L}$, est destinée au dépôt et à la diffusion de documents scientifiques de niveau recherche, publiés ou non, émanant des établissements d'enseignement et de recherche français ou étrangers, des laboratoires publics ou privés. 


\author{
Classification \\ Physics Abstracts \\ $8.814-8.818-8.550$
}

\title{
STRESS INDUCED LINEAR DICHROISM \\ OF ANTIFERROMAGNETIC PEROVSKITES : $\mathrm{KNiF}_{3}, \mathrm{KCoF}_{3}$ AND $\mathrm{RbCoF}_{3}$ \\ I. - MAGNETIC ORIGIN AND EVIDENCE FOR DOMAIN TWIN-WALLS MOVEMENTS
}

\author{
J. FERRÉ, B. BRIAT, R. H. PETIT $\left(^{*}\right)$ \\ Laboratoire d'Optique Physique, 10, rue Vauquelin, 75231 Paris Cedex 05, France
}

R. V. PISAREV

A. F. Ioffe Physico-technical Institute, Leningrad, USSR

and J. NOUET

Faculté des Sciences, Route de Laval, 72000 Le Mans, France

(Reçu le 16 juillet 1975, accepté le 19 janvier 1976)

\begin{abstract}
Résumé. - Nous considérons le dichroïsme linéaire (DL) sous contrainte de $\mathrm{KNiF}_{3}, \mathrm{KCoF}_{3}$ et $\mathrm{RbCoF}_{3}$, au-dessus et au-dessous de la température de Néel. Au-dessus de $T_{\mathrm{N}}$, le dichroïsme sous une contrainte $S$ parallèle à $\langle 001\rangle$ varie linéairement en fonction de $S$ tandis qu'au-dessous de $T_{\mathrm{N}}$ on observe deux comportements différents de part et d'autre de $S_{\mathrm{cr}}$. En particulier, sous une faible contrainte $\left(S<S_{\mathrm{cr}}\right)$, la variation du DL est rapide et réversible. Nous interprétons nos résultats expérimentaux par le déplacement aisé des parois de domaines (parois de mâcle). Ce comportement est confirmé par la faible valeur de l'énergie nécessaire à la formation d'un monodomaine comparée à l'énergie d'un magnon à $\mathbf{k}=0$ déduite d'expériences de diffusion Raman. La valeur de cette énergie est en accord avec nos récentes études sur le dichroïsme circulaire magnétique. Pour une contrainte $\mathbf{S} / /\langle 001\rangle$ supérieure à $S_{\mathrm{cr}}$, dans tous les échantillons, les spins s'alignent suivant la direction $\langle 001\rangle$. Par contre, une contrainte parallèle à $\langle 011\rangle$ ne donne aucun DL pour $\mathrm{KCoF}_{3}$ et $\mathrm{RbCoF}_{3}$. Ceci est en accord avec nos calculs, car le coefficient de magnétostriction $\lambda_{111}$ est très faible. En présence d'une forte contrainte ( $S>S_{\mathrm{cr}}$ ), immédiatement au-dessous de $T_{\mathrm{N}}$, le DL augmente rapidement si la température décroît. Nous concluons que le DL a une origine purement magnétique liée aux séparations énergétiques de l'état fondamental dues à l'interaction d'échange. Le rôle de la contrainte est d'aligner les spins suivant une direction déterminée.
\end{abstract}

Abstract. - We report here on the stress induced linear dichroism (LD) of $\mathrm{KNiF}_{3}, \mathrm{KCoF}_{3}$ and $\mathrm{RbCoF}_{3}$ above and below their Néel temperature. Above $T_{\mathrm{N}}$ we obtain a linear variation of the dichroism with a $\langle 001\rangle$ applied stress $S$, but below $T_{\mathrm{N}}$ we find two different parts for this curve when $S$ increases. Under a small stress $\left(S<S_{\mathrm{cr}}\right)$ the LD increases rapidly and is reversible with $S$. From these experiments, we infer that there is an easy reversible movement of the domain twin-walls. This is confirmed by the small energy required to obtain a single domain in comparison to the $\mathbf{k}=0$ magnon energy deduced from Raman experiments. The value of this energy agrees with our recent magnetic circular dichroism studies. For all samples above $S_{\mathrm{cr}}(\mathbf{S} / /\langle 001\rangle)$ we obtain an untwinned crystal where the spins align along the $\langle 001\rangle$ direction. In agreement with our calculations, no effect is observed for $\mathrm{KCoF}_{3}$ and $\mathrm{RbCoF}_{3}$ under a $\langle 011\rangle$ stress since they have a small $\lambda_{111}$ magnetostrictive coefficient. Under a high stress $\left(S>S_{\mathrm{cr}}\right)$, the LD increases rapidly with decreasing temperature just below $T_{\mathrm{N}}$. We attribute this dichroism to a pure magnetic origin which is related to the exchange splitting in the ground state, the stress being only used to align the spins along a definite direction.

(*) Equipe de Recherche no 5 du C.N.R.S. 
1. Introduction. - Many authors have tried to explain the origin of the birefringence or the linear dichroism (LD) in antiferromagnets [1-3] or in ferromagnets $[4,5]$. However the question is still open as to how much of this birefringence has a purely magnetic origin $[1,3,4]$ and how much is due to magnetostrictive deformation [2]. In an effort to help clarify this point, we reported in earlier papers $[1,6]$ measurements of the linear dichroism induced by an applied uniaxial stress. These measurements were made on cubic antiferromagnets $\left(\mathrm{KNiF}_{3}, \mathrm{KCoF}_{3}\right.$ and $\mathrm{RbCoF}_{3}$ ) in which the magnetostrictive deformations are weak. The dominant effect should be that due to the alignment of spins along the direction of the applied stress.

In the present paper, we discuss in more detail the variation of this linear dichroism (LD) with stress and temperature in these crystals. We show that the characteristic behaviour observed can be understood in terms of the movement of domain twin-walls under stress to produce a monodomain. A similar process has been previously proposed by us [7] to interpret the magnetic circular dichroism under a magnetic field in $\mathrm{KNiF}_{3}$. The dispersion of the LD with frequency was also studied and is reported in a second paper [8].

LD is defined as the difference in absorbance for light polarized parallel and perpendicular to the stress direction respectively. The main advantage of the LD over magnetic birefringence is that the experiment is carried out in absorption regions where essentially one transition is involved, its origin being usually known. Experiments have been performed in the spectral range $13500-35000 \mathrm{~cm}^{-1}$ on single crystals of $\mathrm{KNiF}_{3}\left(T_{\mathrm{N}}=246 \mathrm{~K}\right) \mathrm{KCoF}_{3}\left(T_{\mathrm{N}}=117 \mathrm{~K}\right)$ and $\mathrm{RbCoF}_{3}\left(T_{\mathrm{N}}=101 \mathrm{~K}\right)$ grown by the BridgmanStockbarger method. Crystallographic measurements on cobalt fluoperovskites show the existence of a quadratic distortion below $T_{\mathrm{N}}[9]$; in $\mathrm{KNiF}_{3}$ the deformation does not exceed $10^{-5}$ [9].

2. Experimental results. - The apparatus has been described previously [10]. In the experiments $0.5 \times 5 \times 5 \mathrm{~mm}^{3}$ samples are used and the crosssection of the light beam is about $4 \mathrm{~mm}^{2}$. In this paper we refer mainly to the ${ }^{3} \mathrm{~A}_{2 \mathrm{~g}} \rightarrow{ }^{1} \mathrm{~T}_{2 \mathrm{~g}}$ transition for
$\mathrm{KNiF}_{3}$ and to the ${ }^{4} \mathrm{~T}_{1 \mathrm{~g}}^{\mathrm{a}} \rightarrow{ }^{2} \mathrm{~T}_{1 \mathrm{~g}}$ transition for $\mathrm{KCoF}_{3}$ and $\mathrm{RbCoF}_{3}$ because of their reasonable absorbance for a $0.5 \mathrm{~mm}$ thick crystal. However the same temperature and stress dependence can be observed in all the bands located between 13000 and $25000 \mathrm{~cm}^{-1}$.

In the region of magnetic ordering, we note :

- A sudden increase of the $L D$ and a modification of the shape of the spectrum at $T_{\mathrm{N}}$ (Fig. 1 and ref. [1, 6]) for all samples when $\mathbf{S} / /\langle 001\rangle$. For $\mathbf{S} / /\langle 011\rangle$ such a variation was observed only for $\mathrm{KNiF}_{3}$. For $\mathrm{KCoF}_{3}$ and $\mathrm{RbCoF}_{3}$ we only detect a small stray signal related to the misorientation or to stress inhomogeneities; this prevents the estimate of the true signal when $T<T_{\mathrm{N}}$ for cobalt fluoperovskites.

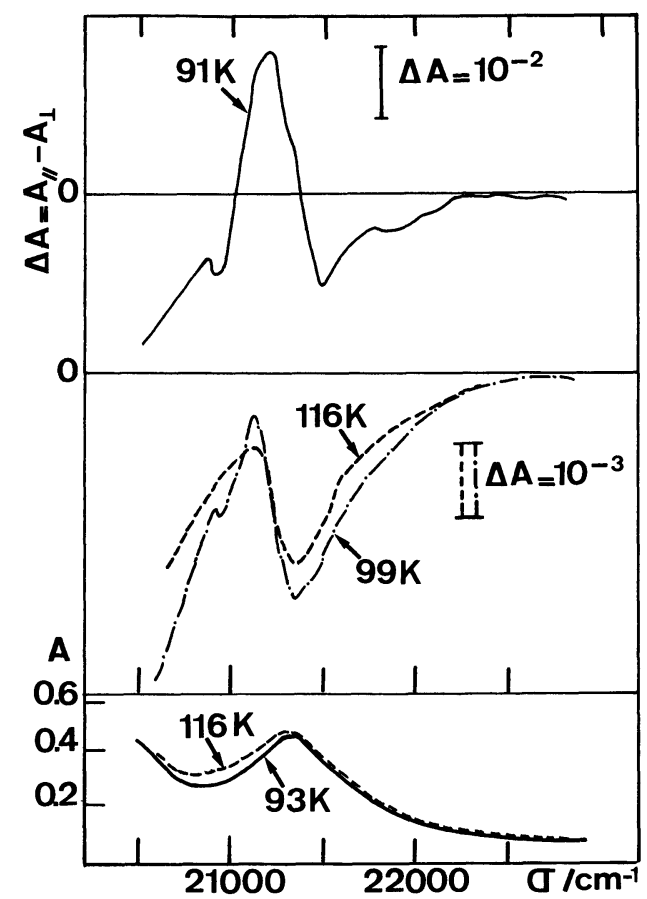

Fig. 1. - Absorption (bottom), LD around $T_{\mathrm{N}}$ for $S=62 \mathrm{kgp} . \mathrm{cm}^{-2}$ (middle) and LD below $T_{\mathrm{N}}$ for $S=34 \mathrm{kgp} . \mathrm{cm}^{-2}$ (top) $(\mathrm{S} / /\langle 001\rangle)$ for $\mathrm{RbCoF}_{3}$.

- A change of the slope of the LD amplitude versus $S$ (Fig. 2 and ref. [1, 6]) for all samples if $\mathbf{S} / /\langle 001\rangle$ at a small value of the stress $S_{\mathrm{cr}}$ (Table I) whatever the light frequency is. The shape of the LD spectra does

TABLE I

Experimental values of $S_{\mathrm{cr}}$ and $K$ for $\mathrm{KNiF}_{3}, \mathrm{KCoF}_{3}$ and $\mathrm{RbCoF}_{3}$ below $T_{\mathrm{N}}$

\begin{tabular}{|c|c|c|c|c|c|c|}
\hline & $\lambda_{100}[9]$ & $\begin{array}{c}S_{\mathrm{cr}}(S / /\langle 001\rangle) / \\
\mathrm{kgp} \cdot \mathrm{cm}^{-2}\end{array}$ & $\begin{array}{c}S_{\mathrm{cr}}(S / /\langle 011\rangle) / \\
\mathrm{kgp} \cdot \mathrm{cm}^{-2} \\
-\end{array}$ & $\begin{array}{l}K(\mathrm{LD}) / \\
\mathrm{erg} \cdot \mathrm{cm}^{-2}\end{array}$ & $\begin{array}{c}\mathbf{k}=0 \\
\text { magnon } \\
\text { frequency } \\
(\text { Raman) }(2 \mathrm{~K})\end{array}$ & $\begin{array}{c}K(\text { Raman }) / \\
\text { erg. } \mathrm{cm}^{-2}\end{array}$ \\
\hline $\mathrm{KNiF}_{3}$ & $\begin{array}{r}\left\langle\overline{10^{-5}}\right. \\
(4 \mathrm{~K})\end{array}$ & $\begin{array}{r}120(242 \mathrm{~K}) \\
70(150 \mathrm{~K})\end{array}$ & $\begin{array}{c}\overline{50} \\
(242 \mathrm{~K} \text { or } 150 \mathrm{~K})\end{array}$ & $\begin{array}{c}\overline{10^{3}} \\
(150 \mathrm{~K})\end{array}$ & $5 \mathrm{~cm}^{-1}[11]$ & $\overline{10}$ \\
\hline $\mathrm{KCoF}_{3}$ & $\begin{array}{c}1.9 \times 10^{-3} \\
(95 \mathrm{~K})\end{array}$ & $20(95 \mathrm{~K})$ & & & $38.5 \mathrm{~cm}^{-1}[12]$ & \\
\hline $\mathrm{RbCoF}_{3}$ & $\begin{array}{c}1.9 \times 10^{-3} \\
(83 \mathrm{~K})\end{array}$ & $20(83 \mathrm{~K})$ & & & $31 \mathrm{~cm}^{-1}[13]$ & \\
\hline
\end{tabular}


not depend on the stress value. Then, at a given temperature we have estimated the LD amplitude for the ${ }^{4} \mathrm{~T}_{1 \mathrm{~g}}^{\mathrm{a}} \rightarrow{ }^{2} \mathrm{~T}_{1 \mathrm{~g}}$ transition on an extremum whose frequency depends of the magnetic order (Fig. 1 and 2). We found a similar behaviour for $\mathbf{S} /\langle 001\rangle$ for $\mathrm{KNiF}_{3}$. We have observed that the $S_{\text {cr }}$ value may vary by a factor two with the sample, depending on its thickness and its origin.

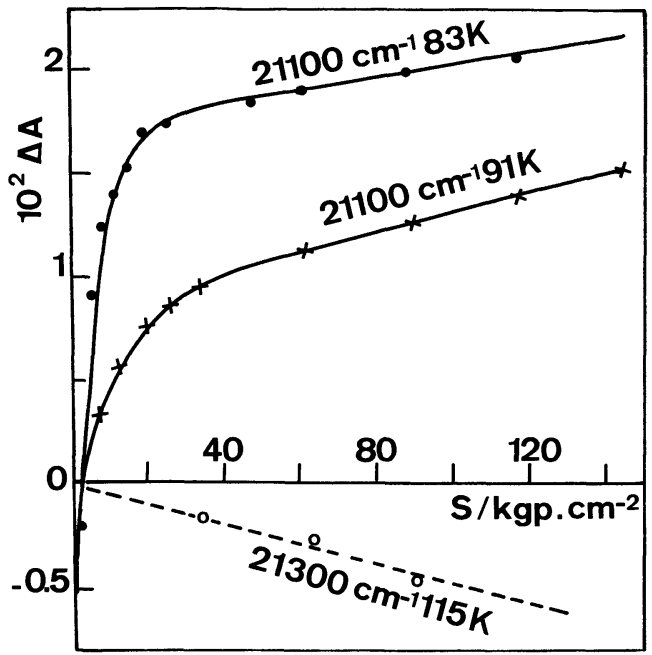

FIG. 2. - Stress dependence of LD in paramagnetic and antiferromagnetic region for $\left.\operatorname{RbCoF}_{3}(S / /<001\rangle\right)$. We give the results for the transition ${ }^{4} \mathrm{~T}_{1 \mathrm{~g}}^{\mathrm{a}} \rightarrow{ }^{2} \mathrm{~T}_{1 \mathrm{~g}}$, as an example.

- The reversibility of the LD versus the stress up to $250 \mathrm{kgp} . \mathrm{cm}^{-2}$ for $\mathrm{KNiF}_{3}$ and $\mathrm{RbCoF}_{3}$ when we have cooled the sample under or without an applied stress. However, for $\mathrm{KCoF}_{3}$, after a cooling under stress followed by a rapid removal of the stress, a signal remains. A slight but rapid temperature variation destroys this metastable equilibrium and the LD then decreases to a low value.

- For $S=0$ there remains a random residual signal due to internal strains.

- The LD varies approximately as the square of the sublattice magnetization $M^{2}$.

A LD momentum analysis cannot be achieved because of the too large thickness of the studied sample. For this case, the LD amplitude at a given frequency does not follow exactly $M^{2}$.

3. Discussion. - 3.1 ORIGIN OF LD UNDER STRESS IN $\mathrm{KNiF}_{3}, \mathrm{KCoF}_{3}, \mathrm{RbCoF}_{3}$. - For these compounds above $T_{\mathrm{N}}$ the shape of the LD is similar to the absorption for each individual spin-orbit component [1]. This behaviour cannot be attributed to a splitting of the excited electronic levels of the $\mathrm{Ni}^{2+}$ ion. The LD under stress above $T_{\mathrm{N}}$ can only arise from either the splitting of the infrared $t_{1 u}$ modes of vibration which assist the transition [1] or to a mixing of the spin orbit excited states via the stress.

If we assume that the photoelastic contribution to the LD below $T_{\mathrm{N}}$ is of the same order of magnitude as in the paramagnetic region, we do not explain the large amplitude change of the LD at $T_{\mathrm{N}}$. Moreover this LD cannot be related to the magnetostriction in $\mathrm{KNiF}_{3}$ because the corresponding deformation $\left(<10^{-5}\right)$ [9] remains small compared to the stress induced deformation $\left(5 \times 10^{-4}\right.$ at $\left.200 \mathrm{kgp} . \mathrm{cm}^{2}\right)$. We therefore conclude that the large $\operatorname{LD}\left(\triangle \mathrm{A} / \mathrm{A} \sim 10^{-1}\right)$ below $T_{\mathrm{N}}$ has a pure magnetic origin, i.e., is closely related to the exchange splitting in the ground state. The stress only orients the spins along a favoured direction, which may be compared to the effect of a magnetic field.

Below $T_{\mathrm{N}}$, for $\mathrm{KCoF}_{3}$ and $\mathrm{RbCoF}_{3}$ [6] the conclusion about the origin of the $\mathrm{LD}$ is the same as in $\mathrm{KNiF}_{3}$ except perhaps for the ${ }^{4} \mathrm{~T}_{1 \mathrm{~g}}^{\mathrm{a}} \rightarrow{ }^{2} \mathrm{~T}_{1 \mathrm{~g}}$ transition (Fig. 1) where the $S$-shaped LD curve indicates that the exchange interaction in the excited state can be significant.

A comparison of the sign of the LD under stress and under a magnetic field in $\mathrm{KNiF}_{3}$ and $\mathrm{RbNiF}_{3}$ [14] for the ${ }^{3} \mathrm{~A}_{2 \mathrm{~g}} \rightarrow{ }^{1} \mathrm{E}_{\mathrm{g}}$ transition, leads us to the conclusion that, below $T_{\mathrm{N}}$, the spins in $\mathrm{KNiF}_{3}$ align along the stress direction $(\mathbf{S} / /<001\rangle)$. This is in agreement with torque measurements [15]. Our results suggest that the spins also align along the stress direction for $\mathbf{S} / /\langle 011\rangle$. For $\mathrm{KCoF}_{3} \mathrm{a}\langle 001\rangle$ stress aligns the spins along its direction [15]. By LD under stress, we have verified that the same behaviour occurs in $\mathrm{RbCoF}_{3}$.

We now consider the temperature dependence of the LD. Below $T_{\mathrm{N}}$ the amplitude of the $\mathrm{LD}$ versus temperature varies approximately as $M^{2}$. This will be demonstrated in section 2 of our paper [8]. Note that a similar variation has been observed recently in birefringence for the cubic antiferromagnet $\mathrm{NiO}$ [16]. From $T_{\mathrm{N}}$ up to higher temperatures, as for $\mathrm{KNiF}_{3}$ [1], the magnetic part of the $\mathrm{LD}$ for $\mathrm{KCoF}_{3}$ and $\mathrm{RbCoF}_{3}$ reaches zero very rapidly within about two degrees. By comparison with heat capacity $[9,17]$ and neutron diffraction measurements on $\mathrm{RbCoF}_{3}$ [18] where short range ordering is still efficient ten degrees above $T_{\mathrm{N}}$, we conclude that the LD does not follow the spin pair correlation function. This agrees with the fact that the variation of the LD is related to the vanishing of domains.

3.2 DESCRIPTION OF THE SPIN-FLOPPING. - For a crystal containing a single magnetic domain, we study now the spin behaviour under stress by minimising the sum of the anisotropy, elastic and magneto-elastic energies. Since a stress preserves the antiparallel alignment of the spins we consider the general expression given for ferromagnets [19] where we take into account only the terms of the fourth power in the cosines of the angle of magnetization. The calculated critical values $S_{\mathrm{cr}}$ necessary to align the spins along the stress direction are summarised in table II using the $\lambda_{100}$ and $\lambda_{111}$ magnetostriction coefficients and the anisotropy constant $K$. If $K$ is negative we should find two successive $S_{\mathrm{cr}}$ values $(\alpha)$ and $(\beta)$, by increasing the 
TABLE II

$S_{\mathrm{cr}}$ values for $\langle 001\rangle$ or $\langle 011\rangle$ stress directions. If $S=0$, for the $(\alpha)$ case the spins lie along the $\langle 111\rangle$ or $\langle 11 \overline{1}\rangle$ axis; in the $(\beta)$ case the spins directions are $\langle\overline{1} 11\rangle$ or $\langle 11 \overline{1}\rangle$.

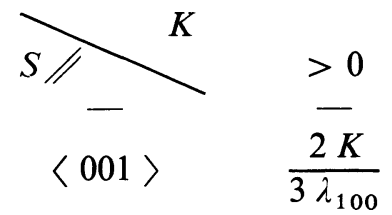

$\langle 011\rangle$

$$
\begin{gathered}
<0 \\
\frac{-2 K}{3 \lambda_{100}} \\
(\alpha) \frac{-2 K}{\lambda_{111}} \\
\text { (B) } \frac{-K}{\lambda_{100}+3 \lambda_{111}}
\end{gathered}
$$

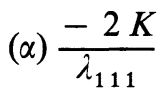

stress along $\langle 011\rangle$. Since $K$ must be positive for the considered fluoperovskites we expect a rapid variation of the LD under a $<001\rangle$ stress at $S_{\mathrm{cr}}$ because of the spin-flopping.

Our experimental results (Fig. 2) show a continuous dependence of the LD with stress and suggest that we have a polydomain structure in cubic antiferromagnets in the absence of a stress, as proposed earlier by Néel [20]. The origin of the spin-flopping in a cubic antiferromagnet differs markedly from that obtained in a uniaxial one because it is due to a reversible movement of the domain twin-walls. As in NiO [21] we conclude that we have an untwinned crystal for $S>S_{\text {cr }}$; the lower part of the curve $\left(S<\mathrm{S}_{\mathrm{cr}}\right)$ (Fig. 2) is related to the displacement of the twin-walls. Other features allow the retention of such a mechanism instead of the rotation of the spins in a single domain :

- The $K$ value deduced from our experiments and calculated from $S_{\mathrm{cr}}$ do not agree with the results deduced from Raman scattering experiments for $\mathrm{KNiF}_{3}$ (Table I). For $\mathrm{KCoF}_{3}$ and $\mathrm{RbCoF}_{3}$ the small value of $S_{\mathrm{cr}}$ is not consistent with the rather large $\mathbf{k}=0$ magnon frequencies (Table I).

- We found a dispersion of the $S_{\mathrm{cr}}$ values for different samples.

If we take into account the interaction with an applied stress $\mathbf{S}$ (direction cosines $\gamma_{1}, \gamma_{2}, \gamma_{3}$ ), the free energy per unit volume of the crystal has been defined as [19] :

$$
\begin{aligned}
F=F_{\mathrm{S}}+F_{\mathrm{A}}=- & \frac{3}{2} \lambda_{100} S\left(\alpha_{1}^{2} \gamma_{1}^{2}+\alpha_{2}^{2} \gamma_{2}^{2}+\alpha_{3}^{2} \gamma_{3}^{2}\right) \\
& -\frac{3}{2} \lambda_{111} S\left(2 \alpha_{1} \alpha_{2} \gamma_{1} \gamma_{2}\right. \\
& \left.+2 \alpha_{2} \alpha_{3} \gamma_{2} \gamma_{3}+2 \alpha_{3} \alpha_{1} \gamma_{3} \gamma_{1}\right) \\
& +K\left(\alpha_{1}^{2} \alpha_{2}^{2}+\alpha_{2}^{2} \alpha_{3}^{2}+\alpha_{3}^{2} \alpha_{1}^{2}\right)
\end{aligned}
$$

where $\alpha_{1}, \alpha_{2}, \alpha_{3}$ stand for the direction cosines of the magnetization.

$F_{\mathrm{S}}$ comes from the stress effect and $F_{\mathrm{A}}$ contains both the magnetoelastic and elastic energy. The expression of the anisotropy coefficient $K$ is given in [19] and the $\lambda$ 's are the magnetostrictive coefficients.
Without stress the easy magnetization directions are related to the sign of $K$. In our case, $K$ is positive and the spins are aligned along the $x, y$ and $z$ four-fold axes of the crystal giving rise three kinds of domains [15] labelled $d_{x}, d_{y}$ and $d_{z}$.

Under $\mathrm{a}\langle 001\rangle$ stress $\alpha_{3}=\cos \theta$ and $F_{\mathrm{S}}$ can be expressed by

$$
F_{\mathrm{S}}=-\frac{3}{2} \lambda_{100} S \cos ^{2} \theta .
$$

If we consider the case of two kinds of domains $d_{z}$ and $d_{x}$ (or $d_{y}$ ) the spin movement occurs in the $z x$ (or $z y)$ plane and :

$$
F_{\mathrm{A}}=\frac{K}{4} \sin ^{2} 2 \theta
$$

In order to interpret our results we can follow Hirakawa et al. [15] who introduce a restoring force proportional to the displacement $x$ of the wall which separates a $d_{z}$ from a $d_{x}$ (or a $d_{z}$ ) domain. The variation $\Delta F$ of the total free energy per unit surface is expressed by :

$$
\begin{aligned}
\Delta F=\frac{1}{2} k x^{2}-\frac{3}{2} & \lambda_{100} S\left[(x) \cos ^{2} \theta_{1}-(-x) \cos ^{2} \theta_{2}\right]+ \\
+ & \frac{K}{4}\left[(x) \sin ^{2} 2 \theta_{1}-(-x) \sin ^{2} 2 \theta_{2}\right]
\end{aligned}
$$

where $\theta_{1}$ and $\theta_{2}$ represent the spin direction inside $d_{z}$ and $d_{x}$ (or $d_{y}$ ) domains.

The minimisation of $\Delta F$ with respect to $\theta_{1}, \theta_{2}$ and $x$ leads to $\theta_{1}, \theta_{2}=0+n \frac{\pi}{2}$ and $x=\frac{3}{2 k} S \lambda_{100}$; the size of the $d_{z}$ domains therefore increases at the expense of the $d_{x}$ or $d_{y}$ domains and the wall moves linearly with the stress. There only remains $d_{z}$ domains when $x$ reaches the value $l$ of their width at a stress $S_{\mathrm{cr}}=2 \mathrm{kl} / 3 \lambda_{100}$. These facts are in good agreement with our experimental results (Fig. 2) in particular with the linear variation of the LD versus $S$ for $S<S_{\mathrm{cr}}$. We have also demonstrated that for $S / /\langle 011\rangle$, $S_{\mathrm{cr}}$ varies as $k l / \lambda_{111}$. Thus, the results are formally the same as those reported in table II (for a single domain) if we replace $K$ by $k l$, but it is important to note that the mechanism involved differs markedly. As we have mentioned earlier the twin-wall movement gives a continuous effect under an applied stress, contrary to the classical spin flop inside a single domain.

Since $S_{\mathrm{cr}}$ values for $\mathrm{KNiF}_{3}$ are comparable for $\mathbf{S} / /\langle 001\rangle$ or $\mathbf{S} / /\langle 011\rangle$ we deduce that $\lambda_{100}$ and $\lambda_{111}$ have the same order of magnitude. On the contrary, the absence of the $\mathrm{LD}$ in $\mathrm{KCoF}_{3}$ and $\mathrm{RbCoF}_{3}$ for $\mathbf{S} / /\langle 011\rangle$ is consistent with the quadratic distortion of the crystal below $T\left(\lambda_{100} \gg \lambda_{111} \simeq 0\right)$.

In contrast to $\mathrm{NiO}$ [21] we had difficulties maintaining untwinned $\mathrm{KCoF}_{3}$ samples after removing the stress. Since the magnetostrictive deformation value is 
similar and the dimension of the domains is large (about $1 \mathrm{~mm}$ ) [22] for the two crystals, we conclude that the reversibility of the spin-flopping in $\mathrm{KCoF}_{3}$ might arise from the high purity of the samples.

\subsection{COMPARISON BETWEEN TWIN-WALLS MOVEMENT} UNDER A STRESS AND UNDER A MAGNETIC FIELD. We have recently demonstrated [7] by the use of magnetic circular dichroism that the magnetic field necessary to flop the spin from the field direction to the plane perpendicular to it is less than 1 tesla. Note that the critical field $H_{\mathrm{cr}}$ is very small compared to $\sqrt{2 H_{\mathrm{E}} H_{\mathrm{A}}}$ where $H_{\mathrm{A}}$ is the anisotropy field and $H_{\mathrm{E}}$ the exchange field. Assuming the same origin, i.e., the movement of domain twin-walls, for the spinflopping under a stress or a magnetic field, we obtain the following relation between $H_{\mathrm{cr}}$ and $S_{\mathrm{cr}}$ :

$$
\begin{aligned}
& \Delta F_{\mathrm{mag}}=-\frac{1}{8 k}\left(\chi_{\perp}-\chi_{\|}\right)^{2} H_{\mathrm{cr}}^{4}= \\
&=\Delta F_{\text {stress }}=-\frac{9}{8 k} \lambda_{100}^{2} S_{\mathrm{cr}}^{2}
\end{aligned}
$$

if $\Delta F_{\text {mag }}$ (or $\Delta F_{\text {stress }}$ ) represents the variation of the free energy in the presence of a magnetic field (or of a stress). Thus, $H_{\mathrm{cr}}=\sqrt{3 \lambda_{100} S_{\mathrm{cr}} /\left(\chi_{\perp}-\chi_{\|}\right)}$and since $\lambda_{100} \leqslant 10^{-5}$ in $\mathrm{KNiF}_{3}$ we deduce $H_{\mathrm{cr}} \leqslant 1$ Tesla.

We therefore conclude that the two sets of experiments are consistent, especially if we take into account the fact that they were not performed on the same crystal and that the critical field (and stress) depends upon the sample.

\subsection{TENTATIVE EXPLANATION FOR THE ABSENCE OF} SATURATION OF LD FOR $S>S_{\mathrm{cr}}$ - The slope of the LD curve versus $S\left(S>S_{\mathrm{cr}}\right)$ may be related to different mechanisms : the photoelastic effect, the modification of the exchange integral $J$ under stress or the incomplete alignment of the spins along the stress direction at $S_{\mathrm{cr}}$. The large difference between the values of the slope above and below $T_{N}$ indicates that the LD depends not only on the photoelastic effect but on other effects also. In $\mathrm{KNiF}_{3}$ the deduced magnetic part of the LD for $S>S_{\mathrm{cr}}$ shows a smaller slope for $\mathbf{S} / /\langle 011\rangle$ than for $\langle 001\rangle$.

This could be due to a larger modification of $J$ for $\mathbf{S} / /\langle 001\rangle$ which is the direction of the superexchange than for $\mathbf{S} / /<011\rangle$. The $\mathrm{KNiF}_{3}$ [23] or $\mathrm{RbCoF}_{3}$ and $\mathrm{KCoF}_{3}$ [9] values of $\partial J / \partial a$ lead to a negligible effect at low temperature on single ion transitions compared to those considered here. The last explanation is that at $S=S_{\text {cr }}$ we have not observed the entire saturation of the LD due to the spin rotation. This would confirm the existence of S-type domains [21] in these perovskites as observed by Lang's method in $\mathrm{KCoF}_{3}$ [22], a fact consistent with the large attenuation of ultrasound below $T_{\mathrm{N}}$ for a stressed crystal, for $S>S_{\mathrm{cr}}$.

4. Conclusion. - We have demonstrated that the stress induced linear dichroism in $\mathrm{KNiF}_{3}, \mathrm{KCoF}_{3}$ and $\mathrm{RbCoF}_{3}$ has a magnetic origin. The stress $S$ is only necessary to remove the domain structure so as to give an untwinned crystal. The corresponding value of $S_{\mathrm{cr}}$ is small compared to the stress which is necessary to rotate the spins in a single domain in an uniaxial antiferromagnet. This is a general effect in cubic antiferromagnets. In particular, we have observed the same behaviour for $\mathrm{RbMnF}_{3}$ where

$$
S_{\mathrm{cr}}(\mathrm{S} / /\langle 111\rangle) \simeq 20 \mathrm{kgp} \cdot \mathrm{cm}^{-2}
$$

is small compared to the value of $400 \mathrm{kgp} . \mathrm{cm}^{-2}$ previously attributed to the spin-flop phenomenon [24]. Thus LD is an interesting and sensitive method to follow twin-wall movements.

The dispersion of the $\mathrm{LD}$ versus the light frequency contains also spectroscopic information which has not been discussed here. This will be considered in the second part of our paper [8] in the light of a comparison of the $\mathrm{LD}$ under stress on $\mathrm{KNiF}_{3}$ and $\mathrm{KCoF}_{3}$ to the magnetic linear dichroism of $\mathrm{Ni}^{2+} / \mathrm{KZnF}_{3}$ and $\mathrm{Co}^{2+} / \mathrm{KMgF}_{3}$ diluted compounds.

Acknowledgments. - We want to thank Mrs Vernazza (Département de Recherches Physiques, Université de Paris VI) who oriented and polished the samples.

\section{References}

[1] Pisarev, R. V., Ferre, J., Duran, J. and Badoz, J., Solid State Commun. 11 (1972) 913.

[2] Jahn, I. R., Phys. Stat. Sol. (b) 57 (1973) 681.

[3] Moch, P. and Balkanski, M., Optical properties of ions in crystals (Interscience) 1967, p. 313.

[4] Pisarev, R. V., Siny, I. G., Kolpakova, N. N. and Yakovlev, Yu., Sov. Phys. JETP 33 (1971) 1175.

[5] Lynch Jr., T. T., Dillon, J. F. and van Litert, L. G., J. Appl. Phys. 44 (1973) 225.

[6] Ferre, J., Briat, B., Pisarev, R. V. and Nouet, J., Proc. Int. Conf. Magn. (Moscow 1973) 2 (1974) 117.

[7] Petit, R. H., Ferre, J. and Nouet, J., J. Physique 36 (1975) 431.
[8] Petit, R. H., Ferre, J., J. Physique 37 (1976) 509.

[9] Nouet, J., Ph. D. Thesis, Paris (1973).

[10] Duran, J., Billardon, M., Pauthier, S. and Ferre, J., C.R. Hebd. Séan. Acad. Sci. B 268 (1969) 1171.

[11] Moch, P. and Dugautier, C., Proc. Int. Conf. Magn. (Moscow 1973) 1 (1974) 185.

[12] Мoch, P. and Dugautier, C., Phys. Lett. A 43 (1973) 169.

[13] Nouet, J., Toms, D. J. and Scott, J. F., Phys. Rev. B 7 (1973) 4874.

[14] Pisarev, R. V., Siny, I. G. and Smolensky, G. A., Solid State Commun. 5 (1967) 959.

[15] Hirakawa, K., Hashimoto, T. and Hirakawa, K., J. Phys. Soc. Japan 16 (1961) 1934. 
[16] Germann, K. H., Maier, K. and Strauss, E., Solid State Commun. 14 (1974) 1309.

[17] Nouet, J., Zarembovitch, A., Pisarev, R. V., Ferre, J. and Lecomte, M., Appl. Phys. Lett. 21 (1972) 4.

[18] Allain, Y., Denis, J., Herpin, A., Leconte, J., Meriel, P., Nouet, J., PlicQue, F. and Zarembovitch, A., J. Physique Colloq. 32 (1971) C1 611.

[19] Herpin, A., Théorie du magnétisme (Presses Universitaires de France, Paris) 1968.
[20] Néel, L., Proc. Int. Conf. on Theor. Phys., Tokyo 1953.

[21] Roth, W. L., J. Appl. Phys. 31 (1960) 2000.

[22] Schlenker, M., Baruchel, J. and Nouet, J., Proc. Int. Conf. Magn. (Moscow 1973) 4 (1974) 368.

[23] Sintani, K., Tomono, Y., Tsuchida, A. and Siratori, K., J. Phys. Soc. Japan 25 (1968) 99.

[24] Eastman, D. E., Phys. Rev. 156 (1967) 645. 